\title{
Identifikasi Kebutuhan Konsumen Produk Mobil Etios Valco Di PT. TMMIN
}

\author{
Ainul Haq ${ }^{1}$, Joerike Joeliana Aditio ${ }^{1}$ \\ ${ }^{1}$ Program Studi Teknik Industri, Fakultas Teknologi Industri, Universitas Gunadarma \\ Jl. Margonda Raya No. 100, Pondok Cina, Depok 16424 \\ Penulis untuk Korespondensi/Email: ainulhaq13@gmail.com
}

\begin{abstract}
Abstrak - Atribut kebutuhan konsumen merupakan hal yang penting dalam kesuksesan suatu produk. Atribut kebutuhan konsumen ini berguna untuk mengetahui apa saja keinginan dan harapan konsumen akan suatu produk yang dihasilkan oleh perusahaan. Sehingga kedepannya produk yang dihasilkan oleh perusahaan akan diminati oleh konsumen serta menarik konsumen untuk membelinya. Selain itu perusahaan akan mampu bersaing dengan perusahaan lainnya dan membuat produknya lebih unggul. PT. Toyota Motor Manufacturing Indonesia (TMMIN) merupakan perusahaan yang bergerak dalam bidang Industri Otomotif. Berdasarkan latar belakang masalah, terdapat 33 atribut kebutuhan konsumen yang akan diidentifikasi, dengan terlebih dahulu dilakukan beberapa uji yaitu uji kecukupan data, uji validitas, dan uji reliabilitas, dengan menggunakan software SPSS 16.0. Berdasarkan hasil beberapa uji tersebut, atribut kebutuhan konsumen semuanya dapat lolos ke tahap selanjutnya. Kemudian akan dilanjutkan ke tingkat kepentingan konsumen dengan melihat dari skala likertnya. Prioritas yang didapat dari hasil tingkat kepentingan konsumen dengan skala likert pada atribut kebutuhan konsumen adalah pemberian garansi terhadap kerusakan mobil dalam waktu yang lama (3 tahun), sistem pengereman auto break system dan tersedianya bengkel resmi di berbagai tempat. Sebaiknya untuk perbaikan yaitu perusahaan melakukan perkembangan sesuai dengan prioritas yang konsumen inginkan dan selanjutnya bisa merujuk ke perkembangan atribut-atribut kebutuhan konsumen yang lainnya.
\end{abstract}

Abstract - Consumer needs attributes are important in the success of a product. This consumer needs attribute is useful to find out what consumer desires and expectations for a product produced by the company. So that in the future the products produced by the company will be in demand by consumers and attract consumers to buy them. In addition, the company will be able to compete with other companies and make its products superior. PT. Toyota Motor Manufacturing Indonesia (TMMIN) is a company engaged in the Automotive Industry. Based on the background of the problem, there are 33 attributes of consumer needs that will be identified, by first doing several tests, namely the data adequacy test, validity test, and reliability testing, using SPSS 16.0 software. Based on the results of several tests, the attributes of consumer needs can all pass to the next stage. Then it will continue to the level of consumer interest by looking at the likert scale. Priority obtained from the results of the level of consumer interest with a likert scale on the attributes of consumer needs is a guarantee of damage to the car in a long time (3 years), auto break system braking system and availability of official workshops in various places. It is better to improve that the company develops according to the priorities that consumers want and can then refer to the development of the attributes of other consumer needs.

Keywords - Consumer Needs Attributes, Priorities

\section{PENDAHULUAN}

$\mathrm{P}$ ersaingan di antara perusahaan akan semakin meningkat dilihat dari banyaknya produkproduk yang dihasilkan di pasaran. Fungsi utama perusahaan manufaktur adalah proses produksi dan operasi untuk mencapai efisiensi, produktifitas dan keuntungan. Persaingan tidak hanya datang dari perusahaan lama tetapi juga datang dari perusahaan 
baru. Salah satu industri yang sedang berkembang pesat saat ini adalah industri otomotif seperti mobil.

Mobil adalah salah satu alat transportasi yang yang banyak digunakan dalam mendukung aktivitas sehari-hari. Permintaan konsumen akan produk ini semakin lama semakin meningkat. Persaingan antara merk yang satu dengan merk yang lain juga semakin meningkat dilihat dari segi kualitas dan harga.

PT. Toyota Motor Manufacturing Indonesia (TMMIN) adalah salah satu perusahaan manufaktur yang bergerak di bidang otomotif yang memproduksi kendaraan, mesin, komponen, dies dan jig. Salah satu produk keluaran PT. TMMIN adalah mobil etios valco. Mobil etios valco dipilih karena sekarang sedang gencar-gencarnya persaingan diantara perusahaan otomotif mengeluarkan mobil kecil yang harganya terjangkau sehingga dapat dibeli oleh masyarakat menengah hingga kebawah.

Persaingan antar perusahaan tidak dapat dihindari tetapi dapat dikurangi dengan cara membuat produk sendiri lebih unggul. Hal yang dapat dilakukan dengan meningkatkan kualitas produk agar sesuai dengan keinginan konsumen adalah dengan terus melakukan pengembangan sehingga produk dapat bersaing dengan produk pesaing lainnya. Identifikasi kebutuhan konsumen dilakukan untuk mengumpulkan atribut kebutuhan konsumen. Selanjutnya mengidentifikasi atribut kebutuhan konsumen tersebut dengan melakukan penilaian berdasarkan skala likert. Kemudian menentukan prioritas yang dibutuhkan oleh konsumen yang akan dikembangkan. Apabila kebutuhan konsumen dapat terpenuhi maka kepuasan konsumen dapat tercipta serta dapat mempengaruhi pandangan konsumen terhadap perusahaan. Selain itu dapat menarik minat konsumen terhadap produk yang dihasilkan.

\section{TINJAUAN PUSTAKA}

\section{Produk Manufaktur}

Produk manufaktur merupakan produk hasil suatu proses (manufaktur) yang dijual oleh produsen ke konsumen yang membutuhkan [1].

\section{Populasi dan Sampel}

Menurut Sujarweni, populasi adalah wilayah generasi yang terdiri atas objek atau subjek yang mempunyai kualitas dan karakteristik tertentu yang ditetapkan oleh peneliti untuk dipelajari dan ditarik kesimpulannya. Sedangkan sampel adalah bagian dari jumlah dan karakteristik yang dimiliki oleh populasi [2].

\section{Uji Validitas dan Reliabilitas}

Uji validitas item digunakan untuk mengetahui seberapa cermat suatu item dalam mengukur objeknya. Sedangkan uji reliabilitas digunakan untuk mengetahui konsistensi alat ukur yang biasanya menggunakan kuesioner [3].

\section{Identifikasi Kebutuhan Konsumen}

Identifikasi kebutuhan konsumen merupakan langkah awal dalam proyek perancangan dan pengembangan produk manufaktur. Sebagai langkah awal, hasil identifikasi ini menentukan keberhasilan langkah pengembangan produk selanjutnya dan pada akhirnya ikut menentukan keberhasilan produk di pasaran [1].

\section{METODE PENELITIAN}

\section{Data Penelitian}

Data penelitian yang dibutuhkan berupa data primer dan data sekunder. Data primer merupakan data yang diperoleh melalui penyebaran kuisioner yang berisi pernyataan yang berhubungan dengan kebutuhan konsumen berdasarkan kondisi produk sekarang dengan target perbaikan yang harus dipenuhi lebih lanjut. Data sekunder merupakan data primer yang sudah diolah lebih lanjut dan disajikan oleh pihak pengumpul data primer baik berupa dokumen ataupun observasi di lapangan.

\section{Teknik Pengumpulan Data}

Pengumpulan data primer dilakukan dengan cara penyebaran kuesioner dan wawancara. Wawancara dilakukan dengan pihak pengembang produk PT. Toyota Motor Manufacturing Indonesia. Kuesioner berguna untuk mengindentifikasikan kebutuhan dan keinginan konsumen. Populasi dari kuesioner tersebut diambil secara acak yang merupakan pengguna mobil etios valco. Sampel penelitian diambil 30 data untuk kuesioner pendahuluan sebagai minimum dalam pengambilan data. Sedangkan data untuk kuesioner keinginan konsumen berdasarkan data yang ada di dealer Toyota Karawang sebanyak 153 data dari 247 populasi yang ada.

\section{Uji Validitas}

Instrumen yang valid adalah alat ukur untuk mendapatkan data yang valid dan dapat digunakan 
untuk mengukur apa yang hendak diukur. Hasil penelitian yang valid bila terdapat kesamaan antara data yang terkumpul dengan data yang sesungguhnya terjadi pada objek yang diteliti. Validitas suatu kuesioner dinyatakan dengan tingkat kemampuan atribut kebutuhan konsumen dalam kuesioner tersebut dengan menggunakan program SPSS 16.0 Kemudian menguji taraf signifikan korelasi yaitu menguji signifikan $r$ yaitu sebagai berikut:

$\mathrm{r}$ hasil $\geq \mathrm{r}$ tabel, maka pertanyaan valid

$\mathrm{r}$ hasil $\leq \mathrm{r}$ tabel, maka pertanyaan tidak valid

\section{Uji Reliabilitas}

Uji reliabilitas digunakan untuk mengukur keandalan dari hasil pengukuran kuisioner. Keandalan disini dapat diartikan bahwa apabila dalam beberapa kali pengukuran terhadap kelompok subjek yang sama diperoleh hasil yang relatif sama, jika aspek yang diukur dalam diri subjek memang belum berubah. Data bisa dikatakan reliabel apabila $\mathrm{R}$ alpha $>\mathrm{r}$ tabel, sedangkan data dikatakan tidak reliabel apabila $\mathrm{R}$ alpha $<\mathrm{r}$ tabel. Digunakan software program SPSS 16.0 dalam menguji reliabilitas pada penelitian ini.

\section{Teknik Pengolahan dan Analisa Data}

Teknik pengolahan data yang digunakan dalam penelitian ini adalah dengan menggunakan Skala likert agar dapat diidentifikasi. Analisa data yang digunakan antara lain yaitu dengan:

1. Fase pertama (mengumpulkan suara pelanggan/ voice of customers)

2. Fase kedua (penilaian berdasarkan skala likert)

3. Fase analisa dan interprestasi

\section{PEMBAHASAN}

\section{Kuesioner Pendahuluan}

Kuesioner pendahuluan merupakan kuesioner tahap awal dalam melakukan suatu penelitian. Data yang dikumpulkan dalam riset ini berupa data primer dan data sekunder. Data primer didapatkan dengan cara menyebarkan kuesioner kepada 30 orang dalam hal ini adalah pengguna mobil etios valco. Kuesioner juga memuat pertanyaan yang bersifat terbuka. Pertanyaan terbuka bertujuan untuk memperdalam mengenai kelemahan dari mobil etios valco, dan juga dilakukan interview baik dengan konsumen maupun dengan manajemen perusahaan untuk memperjelas informasi-informasi yang didapat dari kuesioner. Data sekunder didapat dari data-data eksternal yang sudah dipublikasikan yang diperoleh dari penelitian terdahulu dan literatur. Penelitian secara eksploratif ini bertujuan untuk memahami permasalahan secara lebih mendalam.

Tabel 1. Variabel Berdasarkan Kuisioner Pendahuluan [4]

No. Variabel Keterangan

1. Performance

2. Features

3. Reliability

4. Conformance

5. Durability

6. Serviceability

7. Estetika

8. $\quad$ Perceived
Berhubungan dengan karakteristik operasi pokok dari produk inti yang dibeli, misalnya konsumsi bahan bakar, kemudahan dan kenyamanan dalam mengemudi, dan lain sebagainya

Berhubungan dengan karakteristik sekunder atau pelengkap, misalnya kelengkapan interior dan eksterior seperti dashboard, $\mathrm{AC}$, sound system, power steering, door lock system, dan sebagainya

Berhubungan dengan kemungkinan kecil akan mengalami kerusakan atau gagal dipakai macet, rusak

Berhubungan dengan sejauh karakteristik desain dan operasi memenuhi standar-standar yang telah ada sebelumnya

Berhubungan dengan berapa lama produk tersebut dapat terus digunakan

Berhubungan dengan kecepatan, kompetensi, kenyamanan, mudah direparasi, serta penanganan keluhan yang memuaskan

Berhubungan dengan daya tarik produk terhadap panca indera, misalnya bentuk body mobil, warna, dan sebagainya

Berhubungan dengan ciri dari reputasi produk serta tanggung jawab perusahaan terhadapnya 


\section{Kuesioner Penelitian I}

Kuesioner penelitian I merupakan kuisioner tertutup yaitu kuesioner yang telah dibatasi oleh peneliti sesuai atribut kebutuhan konsumen yang didapat dari kuesioner pendahuluan dan ditentukan dengan skala likert. Data dari konsumen secara umum digunakan untuk mengetahui kebutuhan konsumen akan mobil etios valco. Kebutuhan konsumen akan mobil etios valco tersebut dapat dilihat pada Tabel 2 berikut ini:

Tabel 2. Data Keinginan Pelanggan Terhadap Kualitas Mobil Etios Valco

\begin{tabular}{|c|c|c|}
\hline Variabel Primer & Variabel Sekunder & Variabel Tersier \\
\hline \multirow{31}{*}{$\begin{array}{l}\text { Kualitas Mobil } \\
\text { Etios Valco }\end{array}$} & \multirow{3}{*}{ Performance } & Bobot mobil yang ringan \\
\hline & & Rangka mobil yang kuat \\
\hline & & Kestabilan mobil dalam kecepatan tinggi \\
\hline & \multirow{7}{*}{ Features } & Sistem kemudi EPS (Electronic Power Steering) \\
\hline & & Sistem keamanan dual SRS airbags \\
\hline & & Kaca spion elektrik \\
\hline & & Kamera belakang \\
\hline & & Audio steering switch \\
\hline & & Sensor hujan \\
\hline & & Auto lock system \\
\hline & \multirow{3}{*}{ Reliability } & Mampu mencapai kecepatan tinggi (km/jam) \\
\hline & & Memiliki mesin dengan tenaga yang maksimum \\
\hline & & $\begin{array}{l}\text { Dapat digunakan untuk berbagai kondisi jalan } \\
\text { Sistem pengereman otomatis }\end{array}$ \\
\hline & \multirow{3}{*}{ Conformance } & Kualitas ban yang baik \\
\hline & & $\begin{array}{l}\text { Kondisi lampu depan terang dan baik dalam } \\
\text { kondisi apapun (volt/watt) }\end{array}$ \\
\hline & & $\begin{array}{l}\text { Pemberian garansi terhadap kerusakan mobil } \\
\text { dalam waktu lama ( } 3 \text { tahun) }\end{array}$ \\
\hline & \multirow{2}{*}{ Durability } & Umur mesin tahan lama \\
\hline & & Mesin tahan karat \\
\hline & \multirow{4}{*}{ Serviceability } & Kemudahan memperoleh suku cadang \\
\hline & & Tersedianya bengkel resmi di berbagai tempat \\
\hline & & Kemudahan dalam perawatan mesin \\
\hline & & $\begin{array}{l}\text { Kemudahan dalam mengganti atau menambah } \\
\text { fitur-fitur tambahan }\end{array}$ \\
\hline & \multirow{6}{*}{ Estetika } & Variasi warna yang menarik \\
\hline & & Desain body mobil agresif dan sporty \\
\hline & & Headlamp yang tampil stylish \\
\hline & & Aksen body kit yang aerodinamis \\
\hline & & Desain lampu belakang yang menarik \\
\hline & & Velg yang semakin menarik \\
\hline & \multirow{3}{*}{ Perceived } & Harga terjangkau \\
\hline & & Harga suku cadang yang murah \\
\hline & & Harga jual kembali yang tinggi \\
\hline
\end{tabular}




\section{Populasi dan Sampel}

Jumlah populasi dalam penelitian ini adalah seluruh pengguna mobil etios valco yang membelinya di dealer Toyota Karawang yang berjumlah 247 orang. Dalam penelitian ini penulis mempersempit populasi yaitu jumlah seluruh responden sebanyak 247 orang dengan menghitung ukuran sampel yang dilakukan dengan menggunakan teknik Slovin.

Sampel bertujuan untuk mewakili keadaan populasi yang sebenarnya. Pengujian ini dilakukan pada masing-masing atribut pertanyaan dengan tingkat keyakinan 95\% dan tingkat ketelitian 5\%.

$$
\begin{gathered}
\mathrm{n}=\frac{\mathrm{N}}{1+\mathrm{Ne}^{2}} \\
\mathrm{n}=\frac{247}{\left(1+247 \times 0,05^{2}\right)}=152,70 \approx 153 \text { sampel }
\end{gathered}
$$

Setelah dilakukan perhitungan maka didapatkan nilai $\mathrm{n}=153$ dari 247 data yang sebenarnya. Artinya 153 data dianggap telah mewakili populasi yang sebenarnya dan dapat dilakukan pengolahan data selanjutnya.

\section{Uji Validitas}

Uji validitas adalah suatu langkah pengujian yang dilakukan terhadap isi (content) dari suatu instrumen, dengan tujuan untuk mengukur ketepatan instrumen yang digunakan dalam suatu penelitian. Tujuan uji validitas adalah untuk mengetahui sejauh mana ketepatan dan kecermatan suatu instrumen pengukuran dalam melakukan fungsi ukurnya. Data yang telah di dapat dari kuisioner, selanjutnya di uji ke validitasannya. Pengujian validitas dilakukan dengan menggunakan software SPSS 16.0 menggunakan korelasi bivariatelproduct

momen pearson dengan taraf kepercayaan $95 \%$ dan tingkat ketelitian $(\alpha)$ sebesar 5\%. Korelasi bivariate digunakan untuk mengukur keeratan hubungan di antara hasil pengamatan dari populasi yang mempunyai dua variansi. Tingkat signifikansi yang digunakan dalam penelitian ini sebesar 5\%. Syarat suatu atribut dikatakan valid apabila $r$ hitung $\geq r$ tabel $(0,1577)$. Berikut ini adalah hasil uji validitas kuesioner yang disebarkan kepada pengguna mobil etios valco di dealer Toyota Karawang.

Tabel 3. Uji Validitas Kuisioner Keinginan Konsumen

\begin{tabular}{lcccc}
\hline Korelasi Antara & $\begin{array}{c}\text { Nilai Korelasi } \\
\text { (Pearson } \\
\text { Correlation) }\end{array}$ & $\begin{array}{c}\text { Probabilitas } \\
\text { Korelasi } \\
\text { [Sign. }(2- \\
\text { tailed }]\end{array}$ & $\begin{array}{c}\text { Nilai r } \\
\text { tabel }\end{array}$ & Kesimpulan \\
\hline Performance 1 & 0,668 & 0,000 & 0,1577 & Valid \\
Performance 2 & 0,670 & 0,000 & 0,1577 & Valid \\
Performnace 3 & 0,745 & 0,000 & 0,1577 & Valid \\
Performance 4 & 0,725 & 0,000 & 0,1577 & Valid \\
Features 1 & 0,613 & 0,000 & 0,1577 & Valid \\
Features 2 & 0,424 & 0,000 & 0,1577 & Valid \\
Features 3 & 0,633 & 0,000 & 0,1577 & Valid \\
Features 4 & 0,541 & 0,000 & 0,1577 & Valid \\
Features 5 & 0,428 & 0,000 & 0,1577 & Valid \\
Features 6 & 0,454 & 0,000 & 0,1577 & Valid \\
Features 7 & 0,402 & 0,000 & 0,1577 & Valid \\
Reliability 1 & 0,667 & 0,000 & 0,1577 & Valid \\
Reliability 2 & 0,686 & 0,000 & 0,1577 & Valid \\
Reliability 3 & 0,646 & 0,000 & 0,1577 & Valid \\
Reliability 4 & 0,552 & 0,000 & 0,1577 & Valid \\
Conformance 1 & 0,787 & 0,000 & 0,1577 & Valid \\
Conformance 2 & 0,704 & 0,000 & 0,1577 & Valid \\
Conformance 3 & 0,668 & 0,000 & 0,1577 & Valid \\
Durability 1 & 0,821 & 0,000 & 0,1577 & Valid \\
Durability 2 & 0,756 & 0,000 & 0,1577 & Valid \\
Serviceability 1 & 0,580 & 0,000 & 0,1577 & Valid \\
\hline
\end{tabular}




\begin{tabular}{lcccc}
\hline Korelasi Antara & $\begin{array}{c}\text { Nilai Korelasi } \\
\text { (Pearson } \\
\text { Correlation) }\end{array}$ & $\begin{array}{c}\text { Probabilitas } \\
\text { Korelasi } \\
\text { [Sign. }(2- \\
\text { tailed }]\end{array}$ & $\begin{array}{c}\text { Nilai r } \\
\text { tabel }\end{array}$ & Kesimpulan \\
\hline Serviceability 2 & 0,494 & 0,000 & 0,1577 & Valid \\
Serviceability 3 & 0,757 & 0,000 & 0,1577 & Valid \\
Serviceability 4 & 0,672 & 0,000 & 0,1577 & Valid \\
Estetika 1 & 0,716 & 0,000 & 0,1577 & Valid \\
Estetika 2 & 0,829 & 0,000 & 0,1577 & Valid \\
Estetika 3 & 0,845 & 0,000 & 0,1577 & Valid \\
Estetika 4 & 0,790 & 0,000 & 0,1577 & Valid \\
Estetika 5 & 0,513 & 0,000 & 0,1577 & Valid \\
Perceived 1 & 0,561 & 0,000 & 0,1577 & Valid \\
Perceived 2 & 0,857 & 0,000 & 0,1577 & Valid \\
Perceived 3 & 0,873 & 0,000 & 0,1577 & Valid \\
\hline
\end{tabular}

(Sumber: Olah Data, 2012)

Dari Tabel 3 terlihat bahwa terdapat semua atribut pertanyaan dinyatakan valid. Hal ini dikarenakan nilai probabilitas korelasi lebih kecil dari tingkat ketelitian 0,05. Dimana uji validitas pada kuesioner keinginan konsumen ini digunakan taraf signifikan 0,05 , sehinggga hasil yang diperoleh pada output SPSS adalah valid.

\section{Uji Reliabilitas}

Suatu kuisioner dikatakan reliabel atau handal jika jawaban seorang terhadap pertanyaan adalah konsisten dari waktu kewaktu. Pengujian reliabilitas kuesioner dilakukan dengan metode Alfa Cronbach $(\alpha)$. Metode ini digunakan untuk menguji keandalan atribut yang menggunakan skala likert. Atribut memiliki tingkat reliabilitas yang tinggi jika nilai koefisien yang diperoleh lebih besar dari 0,60 [5]. Pengujian reliabilitas kuesioner persepsi pengguna dilakukan pada masing-masing bagian kuesioner yaitu kuisioner keinginan konsumen dan kuisioner kepuasan konsumen. Adapun atribut pertanyaan yang dapat diolah pada uji reliabilitas ini adalah data yang valid, atau dengan kata lain telah memenuhi kriteria. Berikut adalah hasil uji reliabilitas kuesioner yang disebarkan kepada beberapa pengguna mobil etios valco dari dealer Toyota Karawang. Hasil kuesioner keinginan konsumen diperoleh nilai Alfa Cronbach untuk performance sebesar 0,778, features sebesar 0,693, reliability sebesar 0,761 , conformance sebesar 0,850 , durability sebesar 0,825 , serviceability sebesar 0,741 , estetika sebesar 0,773 , dan perceived sebesar 0,813 hal ini menandakan bahwa data yang diolah reliabel. Alfa Cronbach adalah nilai koefisien keandalan yang berkisar antara 0 sampai 1. Dari hasil yang diperoleh bahwa kedua bagian kuesioner persepsi pengguna telah dikatakan reliable, karena nilai Alfa Cronbach lebih besar dari 0,6.

\section{Kuesioner Penelitian II}

Kuesioner penelitian II adalah kuisioner yang bersifat tertutup. Bertujuan untuk mengetahui tingkat kepentingan dan tingkat kepuasan konsumen dari kuesioner pendahuluan dan kuesioner penelitian I. Berdasarkan kuesioner yang disebarkan kepada 153 responden yang merupakan sampel sesungguhnya dari objek penelitian. Bobot kepentingan kebutuhan konsumen disusun dengan skala likert dan skala yang digunakan adalah $1-5$. Hal tersebut dimaksudkan untuk mengetahui tingkat kepentingan dari tiap-tiap kriteria. Keterangan: (1) Sangat Tidak Penting; (2) Tidak Penting; (3) Cukup Penting; (4) Penting; (5) Sangat Penting. Tingkat kepentingan konsumen digunakan untuk memposisikan setiap keinginan ataupun kebutuhan pelanggan dalam bentuk data kuantitatif dengan tujuan untuk memprioritaskan keinginan konsumen. Pemberian bobot dimulai dari atribut yang sangat penting dengan nilai 5 sampai pada atribut yang sangat tidak penting dengan nilai 1 . 
Tabel 4. Tingkat Kepentingan Konsumen

\begin{tabular}{|c|c|c|c|c|c|c|}
\hline No. & Atribut Kebutuhan Konsumen & $\begin{array}{l}\text { STP } \\
(1)\end{array}$ & $\mathrm{CP}(3)$ & $\mathrm{P}(4)$ & $\mathrm{SP}(5)$ & $\begin{array}{l}\text { Tingkat } \\
\text { Kepentingan }\end{array}$ \\
\hline \multicolumn{7}{|c|}{ Performance } \\
\hline 1. & Bobot mobil yang ringan & & 6 & 65 & 82 & 4,496 \\
\hline 2. & Rangka mobil yang kuat & & 12 & 85 & 56 & 4,287 \\
\hline 3. & $\begin{array}{l}\text { Kestabilan mobil dalam kecepatan } \\
\text { tinggi }\end{array}$ & & 5 & 56 & 92 & 4,568 \\
\hline 4. & Pemakaian bahan bakar yang hemat & & 11 & 37 & 105 & 4,614 \\
\hline \multicolumn{7}{|c|}{ Features } \\
\hline 5. & $\begin{array}{l}\text { Sistem kemudi EPS (Electric Power } \\
\text { Steering) }\end{array}$ & & 12 & 109 & 32 & 4,13 \\
\hline 6. & Sistem keamanan dual SRS airbags & & 1 & 80 & 72 & 4,464 \\
\hline 7. & Kaca spion elektrik & 1 & 24 & 103 & 25 & 3,993 \\
\hline 8. & Kamera belakang & & 10 & 102 & 41 & 4,202 \\
\hline 9. & Audio steering switch & & 6 & 103 & 44 & 4,248 \\
\hline 10. & Sensor hujan & 1 & 22 & 101 & 29 & 4,032 \\
\hline 11. & Auto lock system & & & 69 & 84 & 4,549 \\
\hline \multicolumn{7}{|c|}{ Reliability } \\
\hline 12. & $\begin{array}{l}\text { Mampu mencapai kecepatan tinggi } \\
(\mathrm{km} / \mathrm{jam})\end{array}$ & & 11 & 48 & 94 & 4,542 \\
\hline 13. & $\begin{array}{l}\text { Memiliki mesin dengan tenaga yang } \\
\text { maksimum }\end{array}$ & & 13 & 71 & 69 & 4,366 \\
\hline 14. & $\begin{array}{l}\text { Dapat digunakan untuk berbagai } \\
\text { kondisi jalan }\end{array}$ & & 4 & 39 & 110 & 4,692 \\
\hline 15. & Sistem pengereman otomatis & & 3 & 28 & 122 & 4,778 \\
\hline \multicolumn{7}{|c|}{ Conformance } \\
\hline 16. & Kualitas ban yang baik & & 11 & 48 & 94 & 4,542 \\
\hline 17. & $\begin{array}{l}\text { Kondisi lampu depan terang dan } \\
\text { baik } \\
\text { Dalam kondisi apapun (volt/watt) }\end{array}$ & & 4 & 39 & 110 & 4,692 \\
\hline 18. & $\begin{array}{l}\text { Pemberian garansi terhadap } \\
\text { kerusakan mobil dalam waktu yang } \\
\text { lama ( } 3 \text { tahun) }\end{array}$ & & 3 & 26 & 124 & 4,79 \\
\hline 19. & Umur mesin tahan lama & & 8 & 51 & 94 & 4,562 \\
\hline 20. & Mesin tahan karat & & 9 & 102 & 42 & 4,215 \\
\hline \multicolumn{7}{|c|}{ Serviceability } \\
\hline 21. & $\begin{array}{l}\text { Kemudahan memperoleh suku } \\
\text { cadang }\end{array}$ & & 9 & 93 & 51 & 4,274 \\
\hline 22. & $\begin{array}{l}\text { Tersedianya bengkel resmi di } \\
\text { berbagai tempat }\end{array}$ & & 3 & 33 & 117 & 4,745 \\
\hline 23. & Kemudahan dalam perawatan mesin & & 5 & 46 & 102 & 4,633 \\
\hline 24. & $\begin{array}{l}\text { Kemudahan dalam mengganti atau } \\
\text { menambah fitur-fitur tambahan }\end{array}$ & & 2 & 60 & 91 & 4,581 \\
\hline
\end{tabular}




\begin{tabular}{|c|c|c|c|c|c|c|c|}
\hline No. & Atribut Kebutuhan Konsumen & $\begin{array}{c}\text { STP } \\
(1)\end{array}$ & $\begin{array}{l}\mathrm{TP} \\
(2)\end{array}$ & $\mathrm{CP}(3)$ & $\mathrm{P}(4)$ & $\mathrm{SP}(5)$ & $\begin{array}{c}\text { Tingkat } \\
\text { Kepentingan }\end{array}$ \\
\hline \multicolumn{8}{|c|}{ Estetika } \\
\hline 25. & Variasi warna yang menarik & & & 32 & 55 & 66 & 4,222 \\
\hline 26. & $\begin{array}{l}\text { Desain body mobil agresif dan } \\
\text { sporty }\end{array}$ & & & 14 & 50 & 89 & 4,49 \\
\hline 27. & Headlamp yang tampil stylish & & & 10 & 56 & 87 & 4,503 \\
\hline 28. & Aksen body kit yang aerodinamis & & & 7 & 62 & 84 & 4,503 \\
\hline 29. & $\begin{array}{l}\text { Desain lampu belakang yang } \\
\text { semakin menarik }\end{array}$ & & & 16 & 53 & 84 & 4,444 \\
\hline 30. & Velg yang semakin menarik & & & 27 & 91 & 34 & 4,032 \\
\hline \multicolumn{8}{|c|}{ Perceived } \\
\hline 31. & Harga terjangkau & & & 7 & 62 & 84 & 4,503 \\
\hline 32. & Harga suku cadang yang murah & & & 16 & 53 & 84 & 4,444 \\
\hline 33. & Harga jual kembali yang tinggi & & & 14 & 50 & 89 & 4,49 \\
\hline
\end{tabular}

(Sumber: Olah Data, 2012)

Berdasarkan hasil penyebaran kuesioner yang telah dilakukan, maka dapat dihitung tingkat kepentingan konsumen dengan cara melihat jumlah skala terbanyak dari responden yang diambil untuk tiap kebutuhan konsumen. Berdasarkan data tingkat kepentingan konsumen yang paling utama adalah pemberian garansi terhadap kerusakan mobil dalam waktu yang lama (3 tahun) yaitu dengan nilai 4,790. Sedangkan data tingkat kepentingan konsumen yang paling rendah adalah kaca spion elektrik yaitu dengan nilai 3,993 dan ada beberapa tingkat kepentingan konsumen dengan nilai yang sama.

$$
\begin{aligned}
\text { Tingkat Kepentingan } & =\frac{\sum(\text { Number of Respondents at Perfomance Value })}{\text { Total Number of Respondents }} \\
& =\frac{[(6 \times 3)+(65 \times 4)+(82 \times 5)]}{153} \\
& =\frac{688}{153}=4,496
\end{aligned}
$$

\section{Penentuan Prioritas}

Berdasarkan keinginan konsumen selanjutnya dilakukan penentuan prioritas untuk menentukan sasaran utama pada pengembangan kualitas mobil etios valco. Selain itu strategi prioritas ini juga di tunjukkan agar PT. Toyota Motor Manufacturing Indonesia mampu memberikan kepuasan konsumen di masa depan. Hasil dari tingkat kepentingan konsumen dengan skor tertinggi dan merupakan prioritas adalah pemberian garansi terhadap kerusakan mobil dalam waktu yang lama (3 tahun). Langkah yang harus diambil oleh perusahaan adalah melakukan pengembangan pada atribut yang merupakan prioritas kemudian melakukan pengembangan pada atribut-atribut lainnya.

Atribut kebutuhan konsumen dengan nilai terendah atau prioritas paling akhir adalah kaca spion elektrik. Mungkin konsumen tidak terlalu mementingkan atribut ini, karena dianggap atribut lain yang sebaiknya dikembangkan terlebih dahulu. Pada tabel 6 dapat dilihat bahwa terdapat nilai yang sama pada tingkat kepentingannya karena hasil perhitungan dari skala kepentingannya serta pengambilan 3 angka di belakang koma. Nilai yang sama pada tingkat kepentingan tersebut dapat dilakukan penelitian lanjutan dengan bantuan AHP (Analytical Hierarcy Process). AHP pada dasarnya didesain untuk menagkap secara rasional persepsi orang yang berhubungan erat dengan permasalahan tertentu melalui prosedur yang didesain untuk sampai pada skala priferensi diantara berbagai set alternatif [6]. 
Tabel 5. Prioritas Tingkat Kepentingan Konsumen

\begin{tabular}{|c|c|c|c|c|c|c|c|c|}
\hline No. & Atribut Kebutuhan Konsumen & $\begin{array}{l}\text { STP } \\
(1)\end{array}$ & $\begin{array}{l}\mathrm{TP} \\
(2)\end{array}$ & $\begin{array}{l}\mathrm{CP} \\
(3)\end{array}$ & $\begin{array}{l}\mathrm{P} \\
(4)\end{array}$ & $\begin{array}{l}\text { SP } \\
(5)\end{array}$ & $\begin{array}{c}\text { Tingkat } \\
\text { Kepentingan }\end{array}$ & $\begin{array}{l}\text { Rang } \\
\text {-king }\end{array}$ \\
\hline 1. & $\begin{array}{l}\text { Pemberian garansi terhadap kerusakan } \\
\text { mobil dalam waktu yang lama ( } 3 \text { tahun) }\end{array}$ & & & 3 & 26 & 124 & 4,79 & 1 \\
\hline 2. & Sistem pengereman otomatis & & & 3 & 28 & 122 & 4,778 & 2 \\
\hline 3. & $\begin{array}{l}\text { Tersedianya bengkel resmi di berbagai } \\
\text { tempat }\end{array}$ & & & 3 & 33 & 117 & 4,745 & 3 \\
\hline 4. & $\begin{array}{l}\text { Dapat digunakan untuk berbagai kondisi } \\
\text { jalan }\end{array}$ & & & 4 & 39 & 110 & 4,692 & 4 \\
\hline 5. & $\begin{array}{l}\text { Kondisi lampu depan terang dan baik } \\
\text { dalam kondisi apapun (volt/watt) }\end{array}$ & & & 4 & 39 & 110 & 4,692 & 4 \\
\hline 6. & Kemudahan dalam perawatan mesin & & & 5 & 46 & 102 & 4,633 & 5 \\
\hline 7. & Pemakaian bahan bakar yang hemat & & & 11 & 37 & 105 & 4,614 & 6 \\
\hline 8. & $\begin{array}{l}\text { Kemudahan dalam mengganti atau } \\
\text { menambah fitur-fitur tambahan }\end{array}$ & & & 2 & 60 & 91 & 4,581 & 7 \\
\hline 9. & Kestabilan mobil dalam kecepatan tinggi & & & 5 & 56 & 92 & 4,568 & 8 \\
\hline 10. & Umur mesin tahan lama & & & 8 & 51 & 94 & 4,562 & 9 \\
\hline 11. & Auto lock system & & & & 69 & 84 & 4,549 & 10 \\
\hline 12. & $\begin{array}{l}\text { Mampu mencapai kecepatan tinggi } \\
(\mathrm{km} / \mathrm{jam})\end{array}$ & & & 11 & 48 & 94 & 4,542 & 11 \\
\hline 13. & Kualitas ban yang baik & & & 11 & 48 & 94 & 4,542 & 11 \\
\hline 14. & Headlamp yang tampil stylish & & & 10 & 56 & 87 & 4,503 & 12 \\
\hline 15. & Aksen body kit yang aerodinamis & & & 7 & 62 & 84 & 4,503 & 12 \\
\hline 16. & Harga terjangkau & & & 7 & 62 & 84 & 4,503 & 12 \\
\hline 17. & Bobot mobil yang ringan & & & 6 & 65 & 82 & 4,496 & 13 \\
\hline 18. & Desain body mobil agresif dan sporty & & & 14 & 50 & 89 & 4,49 & 14 \\
\hline 19. & Harga jual kembali yang tinggi & & & 14 & 50 & 89 & 4,49 & 14 \\
\hline 20. & Sistem keamanan dual SRS airbags & & & 1 & 80 & 72 & 4,464 & 15 \\
\hline 21. & $\begin{array}{l}\text { Desain lampu belakang yang semakin } \\
\text { menarik }\end{array}$ & & & 16 & 53 & 84 & 4,444 & 16 \\
\hline 22. & Harga suku cadang yang murah & & & 16 & 53 & 84 & 4,444 & 16 \\
\hline 23. & $\begin{array}{l}\text { Memiliki mesin dengan tenaga yang } \\
\text { maksimum }\end{array}$ & & & 13 & 71 & 69 & 4,366 & 17 \\
\hline 24. & Rangka mobil yang kuat & & & 12 & 85 & 56 & 4,287 & 18 \\
\hline 25. & Kemudahan memperoleh suku cadang & & & 9 & 93 & 51 & 4,274 & 19 \\
\hline 26. & Audio steering switch & & & 6 & 103 & 44 & 4,248 & 20 \\
\hline 27. & Variasi warna yang menarik & & & 32 & 55 & 66 & 4,222 & 21 \\
\hline 28. & Mesin tahan karat & & & 9 & 102 & 42 & 4,215 & 22 \\
\hline 29. & Kamera belakang & & & 10 & 102 & 41 & 4,202 & 23 \\
\hline 30. & $\begin{array}{l}\text { Sistem kemudi EPS (Electric Power } \\
\text { Steering) }\end{array}$ & & & 12 & 109 & 32 & 4,13 & 24 \\
\hline 31. & Sensor hujan & & 1 & 22 & 101 & 29 & 4,032 & 25 \\
\hline 32. & Velg yang semakin menarik & & & 27 & 91 & 34 & 4,032 & 25 \\
\hline 33. & Kaca spion elektrik & & 1 & 24 & 103 & 25 & 3,993 & 26 \\
\hline
\end{tabular}




\section{KESIMPULAN}

Berikut ini adalah kesimpulan dari penelitian ini:

1. Variabel dalam penelitian ini terdiri dari variabel primer, sekunder, dan tersier. Sedangkan atribut yang mempengaruhi kualitas mobil etios valco terdiri atas 8 item yaitu performance, features, reliability, conformance, durability, serviceability, estetika, dan perceived. Selanjutnya dilakukan uji kecukupan data, uji validitas, dan uji reliabilitas, untuk mengetahui kevalidan dan kelayakan data tersebut.

2. Prioritas berdasarkan hasil dari tingkat kepentingan konsumen adalah pemberian garansi terhadap kerusakan mobil dalam waktu yang lama (3 tahun), sistem pengereman otomatis dan tersedianya bengkel resmi di berbagai tempat.

\section{UCAPAN TERIMA KASIH}

Penelitian dapat terselenggara atas kerjasama dengan PT. Toyota Motor Manufacturing Indonesia - Karawang

\section{DAFTAR PUSTAKA}

[1] A. P. Irawan. Perancangan dan Pengembangan Produk Manufaktur. Jakarta: ANDI. 2017.

[2] V. W. Sujarweni, Statistika untuk Penelitian, Yogyakarta: Graha Ilmu, 2012.

[3] D. Priyatno, 2012, Belajar Cepat Olah Data Statistik dengan SPSS, Jakarta: ANDI, 2012.

[4] J. Luhulima, Sejarah Mobil \& Kisah Kehadiran Mobil di Negeri ini, Jakarta: Kompas Media Nusantara, 2012.

[5] I. Ghozali, Aplikasi Analisis Multivariate dengan Program SPSS ( $4^{\text {th }}$ ed.), Semarang: Badan Penerbit-Undip, 2002.

[6] A. F. Falatehan, Analytical Hierarchy Process (AHP), Yogyakarta: Indomedia Pustaka, 2016. 